\title{
TEMPORALIDAD DEL GERUNDIO
}

\section{Lic. José Maria Jiménez Vásquez}

Dentro de la problemática del gerundio, el punto de la temporalidad ocupa un lugar muy importante, ya sea por la posible discusión de ciertos tópicos, como por las vacilaciones y errores que se pueden cometer, debidos al imperfecto conocimiento de este tema. Trataremos, en esta corta investigación, de dar un poco de luz a este problema lingüístico.

El gerundio en sí, sea simple o compuesto, no es apto para expresar tiempo gramatical como 10 hacen las formas personales del verbo, ya que no se dan en él los contrastes de "remoto-irremoto, prospectivo-improspectivo" (1) propios de la categoría de tiempo, ni tiene un formante preciso para indicarlo. En el gerundio simple en sí, el derivativo ndo añade al tema verbal la indicación de un proceso no terminado, es decir, un aspecto durativo, "sin atender a la posibilidad de su término" (2); en el gerundio compuesto, la junción de los dos sintagmas agrega otro valor aspectual: "un límite virtual del proceso (que indica falta de término real) (3). Ahora bien, ese aparente defecto del gerundio considerado en sí mismo, le permite una amplia movilidad, al relacionarlo con las formas personales, pues es capaz de referirse a cualquier tiempo. Este es el tipo de temporalidad del gerundio de que trataremos en este artículo.

\section{A. TEMPORALIDAD DEL GERUNDIO SIMPLE DEPENDIENTE}

\section{Coexistencia o simultaneidad}

"Oyendo a los mares / mezo a mi niño". (G. Mistral, Meciendo).

Lavando en el regato cristalino / cantaban las mozuelas". (José María Gabriel y Galán, El ama). "Le hablé de una mariposa / blanca que vi en el sendero / y ella, dándome una rosa, / me dijo: "¡Cuánto te quiero!" (J. R. Jiménez, Mañana de primavera). El gerundio hace depender su significación temporal de su relación con los respectivos verbos en forma personal y adquiere el tiempo expresado por éstos: "oyendo, mezo"; "lavando, cantaban"; "dando, dijo". En los ejemplos dados, los gerundios expresan una acción o proceso coexistente o simultáneo en relación con el del verbo a que se refieren; pero puede haber diferencias de duración entre la acción denotada por el gerundio y la del verbo. Permítasenos proponer unos ejemplos para aclarar esto:

Siendo Augusto emperador, florecieron las artes y las letras.

Sonando la una, llegó el presidente a la reunión.

Gobernando Herodes la Judea, nació Jesucristo.

Como vemos, la simultaneidad se realiza entre dos hechos durativos (siendo y florecieron), entre dos hechos momentáneos (sonando y llegó) o entre uno durativo, expresado siempre por el gerundio, y otro momentáneo (gobernando y nació).

Cuando la coexistencia es absoluta, en cuanto que las acciones son totalmente simultáneas (tanto en su comienzo como en su duración) puede hacerse una sustitución de unas formas por otras, sin aparente cambio de significado:

Entrando yo, salías tú = Saliendo tú, entraba yo . "Partió de la corte, llevando consigo los caballeros". (Quintana, D. Alvaro) = Partiendo de la corte, llevó consigo a los caballeros".

"Que Menalcas, llorando, rompa su flauta triste". (R. Dario, Elegía pagana) $=$ Que Menalcas llore rompiendo su flauta triste.

$\mathrm{Si}$ los hechos coexistentes no lo son en forma absoluta, ya que uno ha comenzado antes que el otro o el uno supone al otro, el que tenga prioridad temporal o lógica tendrá que ir en gerundio y no cabe la sustitución:

"Estudiando matemáticas las aprendo". (R. A. de 
la Peña, Gramática).

"Y el mago del arte... / entreabriendo los estáticos ojos... / tomó los pinceles". (José Ma. Gabriel y Galán, El cristo de Velázquez).

"Y yo me la llevé al río / creyendo que era mozuela". (García Lorca, La casada infiel).

Aunque existe coexistencia entre los gerundios y las formas verbales flexionales, es imposible la sustitución, ya que "estudiar" es antes que "aprender", "tomó" presupone a "entreabriendo" y creyendo" es causa de "llevé". A nadie se le ocurriría decir: "Aprendiendo matemáticas las estudio", ni "tomando los pinceles entreabrió los ojos", ni "llevándola al río, creí que era mozuela". Bajo el supuesto que fuera posible alguna de estas formas, habría un cambio total del mensaje.

Estos dos hechos anteriores los podemos esquematizar así:

$\begin{array}{llll}\text { A Gerundio } & \text { B } & \text { A' } & \text { Gerundio B' } \\ \text { C Verbo } & \text { D } & \text { C' Verbo D' } \\ \begin{array}{l}\text { Coexistencia absoluta } \\ \text { Posible sustitución }\end{array} & \begin{array}{l}\text { Coexistencia no absoluta } \\ \text { Imposible sustitución }\end{array}\end{array}$

\section{Anterioridad}

"Apartando Ricote a Sancho, se sentaron..." (Quijote, II, 54).

"Quitándose del cuello una riquísima cadena... se la puso a Gonzalo". (Quintana, El Gran Capitán). "En el cristal de un espejo / a los cuarenta me vi, / $\mathbf{y}$, hallándome feo y viejo, / de rabia el cristal rompi". (Campoamor, Los dos espejos).

"Saltando el vallado de piedra, cogi el camino de la montaña", (Isaacs María).

"El ladrón, apoyando la escalera en la ventana, se entró por ella". (Luis Florez, Temas de Castellano).

Los gerundios en estas oraciones expresan hechos inmediatamente anteriores a las acciones de los verbos principales. En efecto, "apartando, quitando, hallando, y apoyando" son pretéritos inmediatos de "sentaron, puso, rompí, cogí y entró", respectivamente.

El gerundio simple de esta clase, por lo general, se usa en el interior de un período para designar un momento posterior a una acción y anterior a la del verbo principal:

"Cerró con esto el testamento, y tomándole un desmayo, se tendió en la cama”. (Quijote, II, 74). "Y al conjuro bajaron los ángeles... / y arraricün- dose plumas de raso / de las alas, pinceles le hicieron". (José María Gabriel y Galán, El Cristo de Velázquez.).

"Pero el hombre no qucría morir, y descendiendo hasta la costa, subió a su canoa". (Horacio Quiroga, A la deriva).

"Con esto se rindió el castillo y don Alvaro, poniendo en él un alcaide de su confianza, prosiguió su marcha contra los Infantes". (Quintana, Don Alvaro de Luna).

Podemos esquematizar las acciones o procesos presentes en los ejemplos, de la siguiente manera:

\begin{tabular}{|c|c|c|c|}
\hline & Gerundio & & \\
\hline $\begin{array}{l}\text { Primer verbo } \\
\text { Cerró }\end{array}$ & $\begin{array}{l}\text { Posterioridad } \\
\text { tomando }\end{array}$ & $\begin{array}{l}\text { Anterioridad } \\
\text { tendió }\end{array}$ & Verbo principal \\
\hline Bajaron & arrancando & hicieron & \\
\hline Quería & descendiendo & subió & \\
\hline Rindió & poniendo & prosiguió & \\
\hline
\end{tabular}

El gerundio simple es apto para expresar anterioridad con respecto al verbo principal, pero sobre todo anterioridad inmediata; ya que, si ésta es mediata, se debe usar el gerundio compuesto. Así, en el ejemplo de Quintana, nos parece mejor: Con esto se rindió el castillo, y don Alvaro, habiendo puesto en él un alcaide de su confianza, prosiguió su marcha contra los Infantes.

Aún más, aunque no consideramos desechable el uso del gerundio simple para la expresión de anterioridad inmediata, creemos que esta función pertenece sobre todo al gerundio compuesto $y$, por tanto, lo mejor sería usarlo en esta forma, como efectivamente se puede hacer en todos los ejemplos dados: Habiendo apartado Ricote a Sancho... etc.

\section{Postcrioridad}

El gerundio de posterioridad constituye un verdadero problema lingüistico, ya que, desde hace más de un siglo, ha sido debatido por diversos gramáticos, sin haberse llegado hasta el momento a una solucién completamente satisfactoria. Antes de dar nuestro parecer al respecto, trataremos de referirnos, en forma breve, a algunas opiniones de insignes estudiosos del idioma.

Parece ser que Bello fue el primero en condenar el uso del gerundio de posterioridad: "Exjste una práctica que se va haciendo harto 
común y que me parece una de las degradaciones que deslucen el castellano moderno. Consiste en dar al gerundio un significado de tiempo que no es propio de este derivado verbal... No es a propósito el gerundio para significar consecuencias o efectos, sino las ideas contrarias" (4).

Cuervo, siguiendo a Bello, dice: "E1 gerundio denota siempre un hecho o bien coexistente con respecto al denotado por el verbo a que acompaña,... o bien inmediatamente anterior... Sería incorrecta una frase de tenor de ésta: "Dictóse la sentencia el viernes, verificándose la ejecución al día siguiente"; porque la ejecución es un acto posterior al de la sentencia" (5).

La Real Academia condena también el gerundio de posterioridad: "Denota el gerundio simple coincidencia de tiempo o tiempo inmediatamente anterior, nunca posterior" (6).

Gili y Gaya es también del parecer que el gerundio no puede usarse para expresar posterioridad: "La acción verbal que el gerundio indica no puede ser posterior a la del verbo principal" (7).

La Real Academia, todavía en el Esbozo de una nueva gramática de la lengua española, hace una tajante condenatoria de este tipo de gerundio: "La coincidencia o el contacto temporal estrecho en que se halla el gerundio con el verbo de que depende, hace en general inadecuado al gerundio para significar posterioridad, consecuencià o efecto" (8).

Hasta aquí hemos expuesto opiniones adversas al gerundio de posterioridad, considerado oficialmente incorrecto; veamos otras, en contraposición:

Niceto Alcalá-Zamora se expresa así: "La corrección de semejante empleo del gerundio la discutió Bello basándose en alguna redacción, realmente censurable, por incongruente y falta de lógica y claridad, más no a causa del gerundio... Tal reparo no pucde extenderse... para condenar sistemáticamente el empleo del gerundio referido a consecuencias, y limitarlo sólo a los antecedentes, puesto que lo uno y lo otro son modos o formas de la acción, y por ello misión adecuada y propia de los gerundios. Para expresar consecuencias, se ha venido usando el gerundio desde el Poema del Cid y las Partidas inclusive; y así lo han hecho y lo hacen autores de máxima valía" (9).

El filólogo español Antonio M. Badía Margarit ha hecho un estudio sobre el gerundio de posteridad. Entresaquemos de él algunas ideas en forma de resumen:

El gerundio para expresar posterioridad presenta un uso creciente en nuestra lengua actual. Este uso y su carácter habitual, garantizan que se encuentra plenamente en los cuadros estructurales del verbo español. En efecto Bouzet ha realizado un estudio completo en este aspecto y ha hecho ver la "legitimidad" de este empleo desde un punto de vista exclusivamente lingüístico. Además, Bouzet ha puesto de manifiesto la antigüedad del gerundio usado así: documentado desde el siglo XIV, se encuentra en todas las épocas de la historia de la lengua (10).

Vistas estas opiniones, unas en contra y otras a favor, propondremos algunos ejemplos del uso del gerundio de posterioridad para hacer ver hasta dónde hay razón en condenarlo y hasta dónde no la hay.

a. "Salió de la estancia dando un fuerte portazo". (Real Academia, Esbozo de una nueva gramática de la lengua española, p. 488).

b. "Abrió la boca descomunal, lanzando otro bramido". (José María de Pereda, Peñas arriba).

c. "Se fue a la caballeriza, siguiéndole todos los que allí se hallaban". (Quijote, II, 53).

d. "Y volvió a marcharse Augusto, encontrándose al poco rato en el paso de la Alameda". (Unamuno, Niebla, cap. I).

e. "Los aros comenzaron a revolotear, y el Marquesito, con gran amor propio, los recogió todos sin perder una sola vez, ganándose una ovación delirante..." (R. Gómez de la Serna, El Marquesito del Circo).

f. "Y en esta vida perseveró treinta años, acabándola santísimamente". (Granada, Símbolo de la fe).

g. "Metió la carta en el sobre, cerrándolo a continuación". (María Moliner, Diccionario de uso del español, p. 1, 394).

h. "Guardó parte de su dinero en la caja, metiéndose el resto en el bolsillo". (Idem).

i. "Cambiemos el ejemplo: grueso tiene dos sílabas: grue-so; de la primera grue podemos separar la e, quedando los otros sonidos perfectamente pronunciables". (Cuervo, Notas a la Gramática castellana de Bello, nota 4).

j. "Destilar. (Del lat. destillare) tr. Separar por medio del calor, en alambiques u otros vasos, 
una sustancia volátil, enfriando luego su vapor para reducirla nuevamente al líquido". (Real Academia Española, Diccionario de la lengua española, p. 466).

Todos los gerundios de los ejemplos propuestos expresan acciones posteriores a las denotadas por las otras formas, ya sea porque no pueden llevarse a cabo sin haberse realizado éstas antes, o porque las presuponen. En efecto, no se puede dar el portazo, si antes no se ha salido; no se lanza un bramido, si no se ha abierto la boca; no se puede seguir al que no se ha ido, etc.

Existe un axioma que dice: "Prius est esse quam aliter esse". Según esto, cuando un gerundio significa la manera de verificarse o ejecutarse la acción del verbo principal, tiene que denotar un hecho posterior o, al menos, con posterioridad lógica:

"El fino angora blanco junto a ella se reclina, I rozando con un hocico la falda de Alencon". (Darío, De invierno).

"Salió de la estancia dando un fuerte portazo" (11).

Observamos como "rozando" y "dando" expresan la manera de realizarse "reclina" y "salió", respectivamente. Por tanto, cuando menos los gerundios de posterioridad lógica o de una posterioridad muy inmediata son totalmente correctos.

Si examinamos con detenimiento los gerundios de posterioridad desde el punto de vista de su naturaleza, observamos también que nunca pierden su cualidad básica: el aspecto durativo. Además su acercamiento al verbo principal es muy pronunciado. Esto es, no se pierde totalmente la proximidad de las acciones o procesos, no se da una mediatez total entre una y otra acción, sino más bien una llamativa proximidad. En los ejemplos dados, la acción expresada por el gerundio sigue inmediatamente a la otra, sin que medie entre las dos un tiempo considerable. En cambio, véase estos otros ejemplos:

"Dictóse la sentencia el viernes, verificándose la ejecución al día siguiente". (Cuervo, Apuntaciones críticas, párrafo 326).

"El baile empezará a las siete, terminando a las dos de la mañana". (Tomado de un anuncio oral de baile en Grecia).

Estos gerundios tienen el defecto de una gran separación temporal con respecto a la acción principal.
La mayoría de los gerundios de posterioridad, vistos desde un criterio estilístico, no parecen elegantes, entre las variadas posibilidades de la lengua, y, además, restan concisión y brevedad a la frase. Con todo, debido a la interdependencia de naturaleza imprecisa y recíproca que existe entre éste y el verbo principal, no podemos separar totalmente las acciones. En efecto, estos gerundios cumplen muchas veces función de oración coordinada copulativa y se pueden cambiar perfectamente por ellas:

"Metió la carta en el sobre y la cerró a continuación".

"Dictóse la sentencia el viernes y se verificó la ejecución al día siguiente".

Lo expuesto hasta aquí sobre el gerundio de posterioridad, se puede sintetizar así:

Este uso está condenado por muchos gramáticos y considerado oficialmente incorrecto por la Real Academia Española; algunos gramáticos, en cambio, no lo rechazan totalmente.

Desde el punto de vista estilístico, no parece elegante y preciso. En esto hay unanimidad.

La Real Academia y los otros gramáticos que lo condenan, no dan razones de peso que justifiquen plenamente su rechazo; aún más, en algunos casos se contradicen en la práctica, como se ven en ejemplos antes citados.

Es innegable el hecho de que su uso está actualmente muy extendido y que, inclusive, ha sido utilizado en todos los tiempos por insignes escritores.

El gerundio usado en esta forma no va contra la lógica, ni desdice en nada su característica esencial de acción durativa y proximidad de verbo.

Desde el punto de vista exclusivamente lingüístico, es legítimo, normativamente, según opiniones serias.

En conclusión, creemos que el gerundio es apto para expresar posterioridad, si denota la manera de ejecutarse o realizarse la acción del verbo principal. En cuanto a los gerundios con función de oración coordinada copulativa y que expresan posterioridad inmediata con respecto al verbo principal, no nos parecen totalmente desechables, pero tampoco recomendables. Por lo que mira a gerundios de posterioridad mediata, creemos que deben ser evitados hasta donde sea posible.

Por tanto, no parece totalmente fuera de 
lugar la conveniencia, que la Real Academia revisara los preceptos normativos vigentes sobre el gerundio de posterioridad, ya que consideramos extremada su condenatoria total.

\section{B. TEMPORALIDAD DEL GERUNDIO CON “EN"}

El gerundio latino en su caso ablativo latino podía ir con algunas preposiciones: "de, ab, ex, in". De estos gerundios preposicionales en ablativo sólo pasó a nuestro idioma el que llevaba "in":

"Multum in cogitando dolorem indipiscor". (P1., Trin., 224).

"Fit ut distrahatur in deliberando animus". (Cic., Off., 1, 39).

Este tipo de gerundio tenía en latín significado de simultaneidad y con este sentido pasó directamente al español arcaico:

"Aunque faga el viento en buscando, no les empece". (Montería. 1, 7).

"En rinicndo por el camino, dixo tod esto que avemos dicho". (Crónica General, 271 A, 6).

Como vemos en los ejemplos dados, este gerundio se usó para indicar tiempo simultáneo con el del verbo principal, $y$ en este sentido fue empleado hasta el siglo $\mathrm{XV}$, más o menos. La preposición "en" en este uso primitivo es expletiva, ya que la podemos eliminar sin aparente cambio de sentido.

En la época clásica se usó ya este giro para expresar una acción inmediatamente anterior a la del verbo principal y, a veces, se reforzaba con la repetición del mismo verbo en forma personal precedido de la conjunción "que". Tanto el gerundio con "en", como el que utilizaba la coletilla a que hicimos alusión, fueron muy corrientes en esta épuca y se les consideraba como elegantes desde el punto de vista literario:

"Mandólo matar su muy amado e muy obedescido señor el Rey, el cual en lo mandando matar, se puede con verdad descir que se mató a si mismo". (Cron. de D. Alvaro de Luna, Tit. 128).

"En fin del otoño se volvió el rey a Sevilla con intento de, en pasando el invierno, juntar una gran flota...". (Mariana, Hist. de España, XVII, 2).

"Espera que en tornando / a ser restituido / al ocio ya perdido, / luego verás ejercitar mi pluma". (Garcilaso, Egloga I).

"Y en mirando de fuera, vieron luego / el prado hacia el cual enderezaron". (Garcilaso, Egloga III). "En hallando que halle la historia... la dará luego a la estampa". (Quijote, II, 4).

"Dijo también como su señor, en trayendo que la trujese buen despacho de su señora Dulcinea del Toboso, se había de poner en camino". (Quijote, I, 26).

Actualmente el gerundio con "en" conserva la significación temporal de anterioridad inmediata con respecto al verbo principal, pero su uso es muchísimo más restringido que en la época clásica, aún más, son pocos los ejemplos que se hallan en las obras literarias y tiene sobre todo un matiz popular en su uso corriente. En lugar del gerundio con "en" se usan las expresiones "cuando, en seguida, luego que, en cuanto" etc. $Y$ una forma verbal personal.

"Al fin, en arrojando la montura a un lado del camino, dirigióse el gaucho al árbol" (Sarmiento, Facundo).

"Y es que, en perdiendo el mortal / la fe, juventud y amor, / se mira al espejo y... ¡mal! / se ve en el alma y... ipeor!" (Campoamor, Los dos espejos). "Esta solitaria greca / que me dieron en naciendo". (Gabriela Mistral, Ultimo árbol).

"Pero a los dos días llegó el anciano Bashuto, y en vicndo el sapo dijo:..." (Salarrué, La botija).

"En acabando de pintar esta puerta me voy a comer". (María Moliner, Diccionario de uso del español, p. 1394).

"En meticndosele una cosa en la cabeza, ni las tenazas de Nicomedes se la arrancan". (Refrán).

"En diciendo las verdades se acaban las amistades”. (Refrán).

"En sabiendo que están bien y contentos, ya tengo bastante". (María Moliner, op. cit., p. 1394).

"En dándome Dios salud, no le zafaré nunca el hombro al trabajo". (Oído en una conversación en un autobús de Grecia).

Obsérvese el matiz que existe en los dos últimos ejemplos: en el penúltimo el giro se puede cambiar por la preposición "con" y un infinitivo, o por una expresión restrictiva como "con sólo que, con tal que"; en el último toma un carácter condicional: Si me da Dios salud...etc.

\section{TEMPORALIDAD DEL GERUNDIO SIMPLE INDEPENDIENTE}

"Los Padres Jesuitas, / paseando de arriba 
para abajo para arriba". (Rafael Montesinos. El colegio).

"El sol cabrilleando en la llanura". (José María Souviron, Junto a la playa abierta).

"Un aire frío. Aldebarán luciendo" (Leopoldo de Luis, Salida del Colegio).

"Yo, sobre el suelo, pensando". (José Suárez Carreño, El soldado y su muerto).

"Paulo VI presidiendo el Concilio Vaticano II". (Rótulo de un cuadro).

"Yo limpiando y tú ensuciando". (Expresión escuchada a Thais Hidalgo).

Cuando se utiliza el gerundio en forma independiente, como en los ejemplos propuestos, éste expresa una acción o proceso en transcurso, es decir, con aspecto durativo, pero sin denotación de tiempo gramatical.

En este caso, el gerundio no hace referencia a un verbo principal determinado, sino que, o supone un contexto que denote representación o percepción, o incluye elípticamente una forma personal del verbo "estar".

\section{TEMPORALIDAD DEL GERUNDIO COM- PUESTO}

"Y habiendo buscado a alguien que me explicase bien la pintura, compuse estos cuatro libros". (Valera, Dafris y Cloe).

"Habiendo quedado desierta la ciudad, se tomaron previsiones para repoblarla". (Andrés Bello, Gramática, p. 233).

"La sombra que, / la forma al cuerpo hurtada, / dejó de ser, habiéndose partido". (Lope de Vega, La discreta venganza).

"Habiendo terminado su discurso, recibió una lluvia de aplausos". (Radio Reloj, Noticiero del 16 de setiembre de 1976).

El gerundio compuesto (habiendo + participio) expresa la acción o proceso como acabado, por lo que se le llama también gerundio perfecto. La temporalidad denotada por él, es siempre de anterioridad con relación al tiempo del verbo principal, pero puede referirse a un hecho remoto o relativamente próximo. Esto se capta muy bien en los ejemplos dados: en los dos primeros, la anterioridad expresada por los gerundios es mediata o remota; mientras que en los otros dos, es inmediata o próxima.
En algunos casos, es posible suprimir al gerundio compuesto la forma "habiendo". Entonces se convierte en un participio pasivo en construcción absoluta: habiendo leído el libro, lo guardé = Leído el libro, lo guardé.

\section{E. TEMPORALIDAD DEL GERUNDIO PERI- FRASTICO}

"Habiendo de recibir el grado de doctor, debes sujetarte a las pruebas universitarias". (R. A. de la Peña, Gramática Española).

"Habiendo tú de venir tan pronto, es mejor que te esperemos". (María Moliner, Diccionario de uso del español, p. 1395).

"Estando leyendo el periódico, oí que me llamaban a gritos". (Oído en una narración popular en San José).

"Habiéndole estado mirando uno de ellos con mucha atención, arremetió a él ..." (Quijote, II, 54).

Cuando el gerundio perifrástico tiene la fórmula "habiendo + de + infinitivo" siempre expresa idea de futuro con respecto al verbo principal. En los otros casos, el gerundio de este tipo se comporta como simple o imperfecto (si el verbo auxiliar sobre el que se forma es un infinitivo simple: estar leyendo: estando leyendo), o como compuesto o perfecto (si su base es un infinitivo compuesto: haber estado mirando: habiendo estado mirando).

\section{F. TEMPORALIDAD DEL GERUNDIO EN PE. RIFRASIS}

"Y las doradas abejas / iban fabricando en él / con las amarguras viejas, ! blanca cera y dulce miel". (Antonio Machado, Inventario galante).

"Las campanas todas de la tierra están doblando". (J. R. Jiménez, Granados en cielo azul...).

"Luego se fue vistiendo / de no sé qué ropajes; / y la fiui odiando, sin saberlo". (J. R. Jiménez, Poesía).

"Y las palabras me responden oscuramente como si algo muy profundo estuviera vibrando". (Leopoldo Panero, Quizá mañana).

"Pero el roce irá gastando día tras día / su materia carnal". (Luis Rosales, Tú, si los llamaras). 
El tiempo expresado por el gerundio en estas perífrasis, depende exclusivamente de la temporalidad en que estén las formas finitas del verbo auxiliar; en otros términos, el gerundio toma el tiempo del verbo a que se vincula. Así podemos decir que "fabricando" tiene el tiempo de "iban"; "doblando", el de "están"; "vistiendo", el de "fue"; "odiando", el de "fui"; "vibrando", el de "estuviera" y "gastando", el de "irá".

Afirmamos al inicio de este artículo, que el gerundio en sí mismo es incapaz de expresar tiempo, y así es en efecto. Pero después de haberlo examinado en sus diversas relaciones con formas personales, llegamos a la siguiente conclusión: el gerundio es una forma verbal que al "finitizarse" es capaz de conciliar todos los tiempos gramaticales, o, como dice Alarcos Llorach, posee un "formante cero" (12) con el que puede referirse a cualquier tiempo.

\section{NOTAS}

1. Alarcos Llorach, Emilio: Gramática estructural, p. 110.

2. Ibid., p. 106.

3. Ibid., p. 123.

4. Bello, A. y Cuervo, R.: Gramática castellana, nota al párrafo 446.

5. Cucrvo, Rufino: Apuntaciones críticas sobre el lenguaje bogotano, párrafo 326 .

6. Real Academia Fspañola: Cramática de la lengua española, párrafo 458 , c. sintaxis española, p. 192.
8. Real Academia Fspañola: Esbozo de una nueva gramática de la lengua española, p. 488.

9. Alcalá-Zamora, Niceto: Dudas y temas gramaticales, p. 126.

10. Badía Margarit, Antonio M.: El gerundio de posterioridad, en presente $y$ futuro de la lengua española, p. 295.

11. Fjemplo aceptado como correcto por Real Academia. 107.

\section{BIBLIOGRAFIA}

Alarcos Llorach, Fmilio: Estudios de gramática funcional del Español, Gredos, S. A., Madrid, 1972. 1971.

Gramática estructural, Gredos, S. A., Madrid.

Alcalá-Zamora, Niceto: Dudas $y$ temas gramaticales, Bucnos Aircs, 1946.

Alonso, A.; Henríquez Ureña, P.: Gramática castellana, $23^{\mathrm{a}}$ ed., Losada S.A., Buenos Aires, 1970.

Alonso, Martín: Ciencia del lenguaje y arte del estilo, 9a. ed., Aguilar, Madrid, 1970.

Araujo Gómez, Iernando: Gramática del Poema del Cid, Imprenta de los hijos de M. G. Herńandez, s. 1., 1897.
Criado de Val, Manuel : Fisonomia del idioma español, Aguilar, Madrid, 1962.

Cuervo, Rufino J.: Apuntaciones criticas sobre el lenguaje bogotano, 8a. ed., Bogotá, 1954.

Gili y Gaya, Samuel: Curso superior de sintaxis española, 9a. ed., Spes, S.A., Barcelona, 1964

Lajmonovich, J. D.: "Sintaxis del gerundio español', Dissertation Ahstracts, XXVIII, 1968, p. 3189-A.

Lanehetas, Rutino: Morfologia del verbo castellano, Bailly Bailliere, Madrid, 1897.

Lenz, Rodolfo: La oración y sus partes, 4a. ed., Nas cimiento, Santiago de Chile, 1944. 
Martínez Amador, F.: Diccionario gramatical, Ramón Sopena, Barcelona, 1961.

Menéndez Pidal, R.: Cantar del Mio Cid, texto, gramática $y$ vocabulario, V. I., 3a. ed., Espasa-Calpe, S. A., Madrid, 1954.

Manual de gramática histórica española, 14a. ed., Espasa-Calpe, S. A., Madrid, 1973.

Orígenes del Español, 6a. ed., Espasa-Calpe, S. A., Madrid, 1968.

Moliner, María: Diccionario de uso del Español, Gredos, S. A., Madrid, 1966.

Nebrija, klio Antonio de: Gramática castellana, edición de Galindo Romeo y Ortiz Muñoz, Madrid, 1946.

Padilla, Salvador: Gramática histórico-critica de la lengua española, 6a. ed., Sáenz de Jubera Hermanos, Madrid, 1912.

Peña, R. A. de la: Tratado del gerundio, Editorial Jus, S. A., México, 1955.

Pérez-Rioja, J. A.: Gramática de la lengua española, 6 a. ed., Tecnos, Madrid, 1966.

Pottier, Bernard: Lingüistica moderna y filologia hispánica, Gredos, S. A., Madrid, 1968.

Real Academia Fspañola: Diccionario de la lengua española, 19a. ed., Espasa-Calpe, S. A., Madrid, 1970.

Esbozo de una nueva gramática de la lengua española, rspasa-Calpe, S. A., Madrıd, 1974.

(iramática de la lengua española, 19a. ed., Espasa-Calpe, S. A., Madrid, 1962.

Roca Pons, José: Estudio sobre las perifrasis verbales del Español, Consejo Superior de Investigaciones Científicas, Madrid, 1958.
Salvá, Vicentc: Gramática de la lengua castellana, 14a. ed., Garnier Hermanos, París, 1849.

Seco, Rafael: Manual de gramática española, 9a. ed., Aguilar, Madrid, 1968.

Selva, Juan B.: Trascendencia de la gramática de Bello y el estado actual de los estudios gramaticales, Kapelusz, Buenos Aires, 1950.

Senior, J.: "Sobre R. A. de la Peña: Tratado del gerundio", Nueva Revista de Filología Hispánica, XIII, 1959; pp. 107-109.

Strecker, Karl: Introduction to medieval latin, Finglish translation and revision by Robert B. Palmer, Dublin, 1971.

Tagliavini, Carlo: Fonetica e morfología storica del latino, 3a. cd., riveduta c aggiornata, R. Patron, Bologna, 1962.

Torres y Gómez, Manuel ફ.: Gramática histórico-comparada de la lengua castellana, Sáenz de Jubera Hermanos, Madrid, 1899.

Tovar, Antonio: Gramática histórica latina, Afrodisio Aguado, S. A., Madrid, 1946.

Väänänen, Veiko: Introducción al latin vulgar, Gredos, S. A., Madrid, 1971.

Valentí l:iol, 1.: Sintaxis latina, 9a. ed., Bosch, Barcelona, 1960.

Vidos Benedek, ト.lemer: Manıal de lingüistica románica, 2a. ed., Aguilar, Madrid, 1968.

Zenoni, Giovanni: Ia sintassi latina, Edizioni Zenoni, Venezia, s. f. 